\title{
PROCEDIMENTOS DE LINGUAGEM COMUNS A MURILO MENDES E FRANCIS PONGE
}

\section{Fernando Fiúza Moreira}

Resumo: Partindo do princípio formulado por Octávio Paz de que "a literatura ocidental é um tecido de relações", este ensaio repertoria alguns procedimentos de linguagem comuns a uma fase da obra do poeta brasileiro Murilo Mendes (1901-1975), composta por três livros (A idade do serrote, Convergência e Poliedro), e à obra do poeta francês Francis Ponge (1899-1988). A pista para tal comparação foi fornecida textualmente por um dos comparados - Murilo Mendes. A forma com que os poetas dispõem da linguagem e os possiveis sentidos desta disposição para a poética das respectivas línguas é o objetivo que norteia o presente trabalho.

Palavras-chave: Literatura comparada; poesia do século XX; Murilo Mendes; Francis Ponge.

O mérito de um estudo comparativo não repousa apenas no fato de ele ser inédito - a abundância da produção intelectual torna quase impossível o ineditismo se não de um estudo, ao menos da idéia do estudo. Sendo a comparação uma das três operações mentais mais freqüentes (as outras sendo a indução e a causalidade), um leitor de certa quilometragem livresca estabelecerá naturalmente conexões, correspondências, equivalências, semelhanças e diferenças significativas entre autores de seu repertório, mesmo que não seja um especialista ou estudioso da literatura. O mérito, pois, encontra-se antes no aprofundamento da análise das correspondências do que no ineditismo da

- Doutor em Literatura pela Université Stendhal Grenoble-3 com a tese L'Écriture de Ponge et de Cabral (2000). Atualmente professor adjunto da Faculdade de Letras e do Programa de Pós-Graduação da Universidade Federal de Alagoas. Este trabalho foi resultado de uma pesquisa ("Estudos comparativos dos procedimentos de linguagem na poesia do séc. XX") financiada pelo CNPq com uma bolsa de recém-doutor durante os anos 2001-2003. 
idéia, ou seja, encontra-se na busca dos motivos pelos quais essas correspondências se dão, no mapeamento do ambiente literário dos autores comparados, na cogitação dos sentidos possíveis que determinada postura ética e estética do autor teve em relação à poética da língua em que escreveu etc. Esses procedimentos de análise fariam do leitor-ensaísta "um detetive, um caçador à procura de indícios que lhe permitirão dar um sentido à história" (COMPAGNON, 2001, p. 132).

Sendo a literatura ocidental, segundo Octávio Paz, "um tecido de relações" (PAZ, 1976, p. 161), e, em particular, a poesia ocidental um gênero praticado por homens cultos, o jogo de influências múltiplas, o trânsito entre autores e obras são de evidência epidérmica. Os índices de correspondências são dados pelos próprios poetas que não se pejam em deixar evidentes as marcas de influências, de "leituras fortes" (MORICONI apud RIBEIRO, 1997, p. 60), de reescrituras, num jogo intertextual que é uma das marcas da grande arte - quando se narcotiza o mito ingênuo, de origem romântica, da genialidade autógena.

O propósito deste ensaio é, portanto, o aprofundamento de uma constatação feita não só por um dos comparados, no caso, Murilo Mendes, mas por outros estudiosos da poesia', como João Alexandre Barbosa, Júlio Castañon Guimarães, Ítalo Moriconi e Fábio Weintraub, sobre a re-escritura de certos temas e a adoção de certos procedimentos de linguagem pongianos por parte do poeta mineiro.

Pelo espaço que nos cabe, circunscreveremos este trabalho a quatro anos da produção muriliana, aqueles que vão de 1963 a 1966 (como pode ser visto em Poesia completa e prosa ${ }^{2}$ ), e a três livros: $A$ idade do serrote (publicado em 1968), Convergência (em 1970) e Poliedro (em 1972). É neles (nos anos e nos livros) onde se encontra a "leitura forte" que Murilo Mendes faz de Francis Ponge.

Ver bibliografia no final.

2 MENDES, Murilo. Poesia completa e prosa. Rio de Janeiro, Nova Aguilar, 1995, volume organizado por Luciana Stegagno Picchio. A partir de agora, os textos de Murilo Mendes citados trarão apenas os números das páginas entre parênteses, pois foi usada esta edição no presente trabalho. 


\section{Murilo Mendes, leitor de Ponge}

No Centro de Estudos Murilo Mendes (CEMM), vinculado à Universidade Federal de Juiz de Fora, onde se encontra parte do acervo pictórico e da biblioteca do poeta (os livros em língua estrangeira, visto que aqueles em língua portuguesa foram doados à Universidade de Roma), há cinco livros de autoria de Francis Ponge: Proêmes, Liasse, Méthodes, Lyres e Pièces, todos sublinhados e anotados, tanto nas margens quanto no final dos volumes. Isto seria o primeiro indício material de nossa hipótese. Mas tal indício poderia ser descartado caso o texto muriliano não revelasse as marcas dessa leitura, afinal ler não significa necessariamente assimilar procedimentos ou ainda reescrever certos temas utilizados antes por outros.

A primeira indicação de que tal leitura foi feita encontra-se no final do poema que abre a terceira e última parte de Convergência, "Sintaxe", cujo título é "Texto de informação" e datado de Roma, 1964: "Werbernizei-me. Joãocrabalizei-me./Francispongei-me. Mondrianizeime." (p. 706).

Ora, não bastasse confessar a filiação à linhagem e à linguagem de artistas com notória preocupação formal (o compositor Anton Weber, os poetas João Cabral de Melo Neto e Francis Ponge e o pintor Pietr Mondrian), Murilo Mendes adota não só nesse poema, mas nos três livros em questão, procedimentos que evidenciam tal filiação. O que poderia ser apenas uma blague, uma tirada de humor, é um roteiro de leitura dessa fase da obra do poeta.

\section{Alguns temas em comum}

Há duas entradas possíveis para a leitura da presença de Ponge nessa fase de Murilo Mendes. A mais evidente é a leitura temática. Se nos restringirmos aos três livros em questão, vamos encontrar os seguintes temas tratados por Ponge e por Murilo, sendo que a concentração maior dá-se em Poliedro, o mais pongiano dos três, sobretudo suas duas primeiras partes: "Setor microzoo" e "Setor microlições de coisas".

Em "Setor microzoo", encontram-se "O cavalo" (em Ponge, "Le cheval" faz parte de Pièces, um de seus livros que se encontra na biblioteca do CEMM) e "A aranha" (também em Pièces está 
"L'aragnée"). Curiosamente, esses dois animais também são temas de um poema de Cabral, "As formas do nu". Ainda nesse "Setor", há dois textos que, se não possuem os mesmos temas, a estes são afins: "A lagosta" [em Ponge, "La crevette" ("O camarão"), de Le parti pris des choses] e "O peixe" [em Ponge, "L'imparfait ou les poissons volants" (O imperfeito ou Os peixes voadores) de Prôemes, outro dos livros encontrados no CEMM].

Já na segunda parte de Poliedro, "Setor microlições de coisas", o número de temas pongianos retomados por Murilo é significativamente maior: "O ovo" (em Ponge, "L'Oeuf" encontra-se em Nouveau, Nouveau recueil, livro póstumo e poema que, mesmo sendo datado de 1950, só foi publicado em 1986, ou seja, onze anos após a morte de Murilo Mendes, o que o anula como tema reutilizado, mas não como objeto pongiano. É bastante conhecido o poema de João Cabral "O ovo de galinha", o que tornaria "o ovo" um objetotema antes cabralino que pongiano); "O copo" ["Le verre d'eau" ("O copo d'água"), pertence a Méthodes, outro livro encontrado na biblioteca do CEMM]; "A mesa" ["La table", também publicado pela primeira vez após a morte de Murilo,]; "A magnólia" ["Le magnólia" também pertence a Pièces]; "A laranja" ("L'orange," de Le parti pris des choses); "O fósforo" ("L'allumette" está em Lyres, outro dos livros de Ponge lido e anotado por Murilo) e "O telefone" ("L'apareil du téléphone" é de Pièces, livro onde, ao lado de Le parti pris des choses, mais se encontram poemas sobre objetos).

Assim como em "Setor microzoo", neste também são encontrados temas que não são totalmente equivalentes, mas guardam " "Linidades entre si. Se não, vejamos: "A pérola" [em Ponge, "L'huître" ("A ostra"), de Le parti pris], "O lençol" ("L'edredon" vem em Pièces), "Ossos de borboleta" ("Le papillon" é de Le parti pris), e "O pão e o vinho" ("Le pain" pertence ao Parti pris e "Le vin" a Pièces).

Em Convergência, encontram-se também alguns temas que possuem afinidades com temas pongianos, mas, no lugar de objetos e animais, pessoas. O segundo poema de "Grafitos", primeira parte do livro, chama-se "Grafito na pedra de meu pai" (há também em $A$ idade do serrote um texto com o título "Meu pai"). Em Ponge, "La Famille du sage" é o texto que abre Lyres. Escrever sobre o pai não é exclusividade dos dois poetas, nem este poderia ser caracterizado 
como um tema pongiano ou muriliano, mas o que há em comum aos dois é admiração pelos pais, uma gratidão ao incentivo à carreira de escritor que deram aos filhos e nenhuma morbidez de cunho edipiano, tão freqüente na lírica moderna.

Em "Murilogramas", segunda parte de Convergência, há três poetas franceses que também mereceram textos de Ponge: "Murilograma a Baudelaire", "Murilograma a Rimbaud" e "Murilograma a Mallarmé". Os equivalentes seriam: "Baudelaire", texto de juventude (1923) só publicado em 1984 (em Pratiques d'écriture ou l'inachevement perpétuel), o que elimina a influência e confirma as afinidades eletivas entre Ponge e Murilo; sobre Rimbaud, Ponge não escreveu um texto explícito, com título evocativo, mas três de seus mais conhecidos textos possuem uma evidente intertextualidade com Rimbaud: "Les illuminations" à l'OpéraComique" (de Lyres), "Des cristaux naturels" (de Méthodes) et "LePré" (de Nouveau recueil); finalmente, "Notes d'un poème (sur Mallarmé)", que está significativamente sublinhado por Murilo Mendes em seu exemplar de Proêmes.

$\mathrm{Na}$ terceira e última parte de Convergência, "Sintaxe", voltamos a encontrar três temas pongianos: "O vinho", "A pedra" e "As andorinhas". O primeiro já localizamos linhas atrás, o segundo é um dos mais caros a Ponge e o que fecha Le parti pris des choses, "Le galet" (o seixo), depois retomado em outros poemas como "Un rocher" e "Introduction au galet" (ambos de Proêmes); o terceiro, "Les hirondelles" (as andorinhas), encontra-se em Pièces.

Se extrapolarmos o limite que nos impusemos (o de nos ater aos três livros de Murilo), apenas com o intuito de detectar temas abordados por ambos os poetas, ainda veremos: artistas plásticos que suscitaram textos de ambos como Alberto Giacometti, Georges Braque, Picasso e Miró [em Retratos relâmpagos (de M.M.) e em L'atelier contemporain e Nouveau nouveau récueil (de F.P.)]; e um poeta, Lautréamont, que merece de Murilo dois textos, um em português, ainda em Retratos-Relâmpago, e outro em seu livro de poemas escrito em italiano, Ipotesi; já "Le Dispositif MaldororPoésie" encontra-se em Méthodes, e também bastante sublinhado por M.M. 
Esse exaustivo inventário de temas comuns aos dois poetas nos leva a nos interrogar sobre a validade de fazer uma leitura comparativa ancorada sobre tal conceito; afinal, segundo Hugo Friedrich (1991, p. 152), fazendo um paralelo entre a poesia e a pintura modernas,

A invenção do motivo cede lugar à invenção formal. A esta cabe a tarefa de produzir um organismo autônomo que é criado apenas com os próprios meios do quadro, e não com elementos da realidade externa. Assim não só se reduz em geral o número dos motivos, mas o motivo aparece meramente como exercício para variações. Estas são manifestações do estilo intérprete de si mesmo, procedimento este que se encontra também em poesia. Valéry escreveu certa vez que, em sua opinião, a poesia quase coincide com a empresa de 'produzir muitas variações sobre o mesmo tema.

A validade, no entanto, deste inventário de temas em comum pode ser encontrada no fato de que a inclinação do olhar, e conseqüentemente do texto, de Murilo Mendes para objetos corriqueiros, cotidianos, intranscendentes, além de o aproximar do universo de Ponge (que ficou primeiramente conhecido na poesia ocidental como o poeta dos objetos, capaz de escrever sobre a batata, a máquina de lavar, o caixote de feira etc., ou seja, de renovar o repertório temático da poesia através da eleição de objetos antipoéticos), traz ao mundo metafísico-religioso, que pautou boa parte de sua poesia, uma dose de matéria prosaica, ou, como diz Haroldo de Campos, apoiado na tese de Elizabeth Walther sobre Ponge, "uma redução da metafísica a seus motivos concretos" (1992, p. 68). E essa aproximação, esse interesse pelo que é físico, material, tangível, inclui a linguagem. Prova disso são os dois primeiros versos do poema de abertura de Convergência: "Lacerado pelas palavrasbacantes/ Visíveis tácteis audíveis" (p. 625).

A mudança de Murilo Mendes para Roma, onde passou seus últimos dezoito anos (1957-1975), aproximou-o ainda mais de uma corrente de poetas ocidentais que tomou a linguagem por seu lado físico, material (a materialidade da linguagem), da qual fazem parte, só para citar os que mereceram, de uma forma ou de outra, textos seus: Mallarmé, Pound, Graciliano e Cabral. Curiosamente, Ponge, ao 
contrário de tantos outros artistas e poetas, não mereceu de Murilo um único texto. Talvez a homenagem que ele lhe prestou tenha sido tanto a reutilização de temas quanto alguns procedimentos de linguagem, que é o que veremos a seguir.

\section{Alguns procedimentos de linguagem em comum}

a) A Prosa - Antes de $A$ idade do serrote, Murilo Mendes tinha publicado dois livros em prosa, $O$ sinal de Deus (1936) e $O$ discípulo de Emaús (1945), ambos fortemente marcados pelo tom religioso. Se o primeiro contém poemas em prosa à feição francesa que vem desde Baudelaire, o segundo seria antes um conjunto numerado de 754 provérbios, aforismos, enigmas, sentenças oraculares, frases lapidares, assertivas, teoremas, paradoxos, axiomas, breves reflexões críticas sobre alguns autores (Gil Vicente, Camões etc.), a política, o tempo e o espaço. Um livro que o senso comum chamaria de "livro de pensamento", mas que Luciana Stegano Picchio preferiu colocar sob a etiqueta de "poema em prosa" em Poesia completa e prosa.

Essa prosa brasileira de Murilo, no entanto, está muito distante da européia, tanto do ponto de vista da forma, quanto do conteúdo. Não há aqui um juízo de valor. Sua prosa brasileira contém todas as características de sua poesia: rigor formal, "dissonância no campo da imagem", "precedência à imagem sobre a mensagem, ao plástico sobre o discursivo" (Cabral), a discordia concors barroca detectada por Bandeira, que o chamou de "conciliador de contrários" (CAMPOS, 1992, p. 66). O que a torna distante da européia, primeiro, é a dedicação que Murilo deu a esta última (CASTANGON GUIMARÃES, 2001, p. 114-116), e tal dedicação levou-o a inovações formais, a adoção de procedimentos que não tinham sido utilizados anteriormente; segundo, uma guinada temática, como vimos há pouco; terceiro, a ampliação ou ao menos a diversificação de seu público de leitores, visto que sua poesia altamente moderna, ardida, tensa e enigmática relegava-o a um público de iniciados na arte moderna.

Ora, a adoção da prosa como gênero privilegiado deu-lhe uma mobilidade, uma liberdade formal e ao mesmo tempo um humor que de certa forma retoma o humor presente em seus três primeiros livros (Poemas, Bumba-meu-poeta e História do Brasil). 
Os conectores lógico-discursivos, cortados do verso com o intuito de torná-lo mais econômico, tenso e enigmático, podem ser utilizados na prosa sem que esta se torne por isso entrópica, frouxa e óbvia. E traz ainda uma vantagem: todos os procedimentos usados no poema em verso podem ser utilizados na prosa, que os recebe em nome de sua origem humilde e promíscua. A ampliação do leque dos procedimentos de linguagem que a adoção da prosa propicia fez de Murilo um poeta não só capaz de criar vertiginosas imagens, mas de veiculá-las com uma leveza e eficiência raras, não só em português como em outras línguas latinas.

Em sua prosa européia encontramos procedimentos que antes, em seu verso, ou não eram empregados ou, se o eram, eram com muita parcimônia, tais como aliterações vertiginosas, jogos etimológicos e paronomásticos, jogos entre significante e significado, trocadilhos, inversão dos ditos populares, decomposição de palavras, procedimentos que dão à prosa uma riqueza, leveza e polissemia bem mais difíceis de ser empregados no verso com tanta eficiência.

Outro procedimento que a prosa suporta bem melhor que o verso, pelo menos na poesia moderna, é a utilização da narrativa, da anedota, do causo, da fabulação. A idade do serrote é, ao mesmo tempo, um livro, declaradamente, de memórias e um livro de poesia. Tome-se, por exemplo, "Desdêmona" (p. 930-931):

Desdêmona miroares Desdêmona miroares Desdêmona desdenhosa com dois dês e os dedos manipulando homens, dados, cartas de baralho, miroares, penhoares atrevidos, vidros de cheiro homens homens homens; manipulando a mula-sem-cabeça, o cigarro, a torquês; Desdêmona desnuda desarrumada desnalgada desnatada; Desdêmona a vice-putain juiz-forana (a titular era Ipólita); Desdêmona rebelde inconformista rompeu com a família, plantando as coxas na rua do amor industrializado excomungado; Desdêmona desdenhada que poluía noturnamente os meus lençóis, que animatografava os meus sonhos precoces; Desdêmona mirorares Desdêmona mulher: despovoada desfeita revogada poderosa. 
Nesse texto, encontramos a lembrança de uma prostituta apelidada de Desdêmona que trabalhava nas ruas de Juiz de Fora e povoava a imaginação do poeta adolescente. Afora o improvável nome shakespeariano, como o é o raciniano da titular (Ipólita), tudo parece muito corriqueiro, banal. Mas a forma de contar, não. A prosa está repleta de procedimentos mais encontradiços em verso: começo com forte aliteração em /d/, inclusive com a explicitação do procedimento ("Desdêmona desdenhosa com dois dês", onde há dois dês tanto em "Desdêmona" quanto em "desdenhosa"), o que o caracteriza como texto metalingüístico, pois comenta o próprio código empregado; ausência de vírgulas em passagens que a requerem; rimas e assonâncias (miroares/ penhoares, atrevidos/vidros) e repetição ("homens homens homens").

Outro texto, agora de Poliedro, "Frutas da infância e Post", abole as fronteiras entre prosa e verso e poderia tanto estar em $A$ idade do serrote, pelo tom memorialístico, quanto em Convergência, pelo arrojo formal. Mesmo caso de "A luva", em que não há uma história contada, mas uma redefinição fantástica do objeto:

A Luva é uma sociedade secreta que nos ajuda a esconder a mão.

A luva, ser volúvel, solúvel. Chove na luva. Neva na luva. Descalçar o sapato-da-mão: a luva. As luvas de Luísa. As luvas da lua. As loas da luva. A luva lava a mão. Uma luva lava a outra. Uma mulher lava a outra. A mentira deslavada, com luva. A verdade lavada, inconsútil. O homem é um ser lavável, levável, louvável, luvável. (p. 1005).

Todo o poema é foneticamente ancorado nas duas consoantes do título: $/ \mathrm{l} / \mathrm{e} / \mathrm{v} /$. Além do tecido sonoro, são elas que conduzem 0 tecido de significados, que começa em tom de brincadeira e termina em tom grave ao (re)definir o homem.

Essa plasticidade da prosa de Murilo nos remete à prosa de Ponge. Para Jean-Marie Gleize, um dos estudiosos do poeta francês, autor de sua biografia intelectual, "a diluição da poesia em um trabalho de expressão não pode, de nenhuma maneira, ser pensado em termos de formalidade, de regras, de coerções etc. Francis Ponge não é talvez nem mesmo (ou mais) um poeta em prosa." (1995, p. 18) 
Portanto, classificar a prosa européia de Murilo de poema em prosa seria uma meia verdade ou uma simplificação. Segundo a própria organizadora de sua obra, essa prosa européia "já não são os velhos poemas em prosa de matriz simbolista" (p. 30). O mais conveniente talvez seria, portanto, classificar esses textos simplesmente de "prosa", "a prosa do mundo" de Hegel, autor, aliás, citado por Murilo, só que uma prosa farcie de procedimentos de linguagem mais encontradiços em verso, confirmando uma tendência da arte moderna que seria justamente uma corrida contra as regras do cânone estabelecidas pela teoria e crítica literárias. Quando Suzanne Bernard (1959) conseguiu, enfim, em seu monumental trabalho, dar um status acadêmico ao gênero, poetas como Francis Ponge e Murilo Mendes já tinham dado ou estavam prestes a dar um passo adiante, pondo em xeque, mais uma vez, as regras a tanto custo estabelecidas, o que se por um lado é desanimador, por outro é matéria nova a ser investigada e codificada pelos críticos.

b) O emprego do dicionário - Consultar o dicionário é um ato elementar de quem escreve. Adotar seu torneio frasístico, citá-lo ou redefinir o objeto, muitas vezes contra o dicionário, já não o é. É bem verdade que há em todo o poeta, em diversos graus de intensidade, o desejo adâmico de (re)nomear as coisas. Mas a explicitação desse desejo é mais rara e complexa, pois pode facilmente cair na banalidade esquizofrênica.

Ponge, em "My creative method", de Méthodes, livro lido e anotado por Murilo, como vimos, não esconde seu desejo imperativo:

É preciso que meu livro substitua: $1^{\circ}$ o dicionário enciclopédico, $2^{\circ}$ o dicionário etimológico, $3^{\circ} \mathrm{o}$ dicionário analógico (que não existe), $4^{\circ}$ o dicionário de rimas (de rimas interiores, também), $5^{\circ}$ o dicionário de sinônimos, etc., $6^{\circ}$ toda poesia lírica da Natureza, dos objetos, etc (1999, p. 536).

Toda sua obra é pontuada por citações do Littré (o monumental dicionário da língua francesa escrito no século XIX pelo poeta positivista e parnasiano que lhe dá nome), eleito por Ponge sua leitura preferida, e único livro que lia durante uma fase de vacas magras na juventude. 
Já Murilo Mendes adota esse procedimento, tanto de citar quanto de dar a certas passagens dos textos um torneio dicionário, nos livros em prosa escritos na Europa. E esse uso, tanto implícito, quanto explícito, torna-se evidente nestes dois parágrafos de "Peixe", de Poliedro:

Peixe-agulha. Peixe-borboleta. Peixe-cabra. Peixecachorro. Peixe-cana. Peixe-cavalo. Peixe-congo. Peixedo-mato. Peixe-flor. Peixe-lua. Peixe-macaco. Peixemartelo. Peixe-morcego. Peixe-mulher. Peixe-pedra. Peixe-piolho. Peixe-rato. Peixe-roda.

Ai de mim que não inventei nenhum desses nomes. Constam todos do dicionário brasileiro. Aimez-vous les dictionnaires? perguntou Théophile Gautier a Baudelaire, apenas o conheceu (p. 988).

A enumeração por ordem alfabética dos tipos de peixe foi tirada de dicionário, como é explicitado no segundo parágrafo, logo após o lamento ("Ai de mim") por não ter criado tais nomes, de resto tout à fait murilianos. Restringindo-nos a Poliedro, veremos a seguir algumas passagens cujo contorno frasístico remete imediatamente ao dicionário:

* O tigre, mamífero [sic] da família real dos Felídeos, calcula seus atos com rigor extremo; (p. 981)

* A baleia é um cetáceo da dinastia dos Balenídeos de forma quadradoredonda, cor de burro quando foge. (p. 983)

* A girafa pertence em parte ao reino do camelo e ao do pardal, já que seu nome científico é giraffa camelopardalis. Informam-me que este nome vem do árabe zarafah.

Nos dicionários a girafa é vizinha de palavras sedutoras; por exemplo girafalte, com seus sinônimos girafalto e gerifalto. Há mesmo um "gerifalte" letrado. (p. 984)

* O pavão é uma grande ave galinácea da ordem dos Fasianídeos, nome que cheira vagamente a Pérsia ou Grécia, aos dois Pausânidas. (p. 987)

* Segundo o registro civil a lagosta é um crustáceo macruro (de cauda longa), antenas cilíndricas, originário da família dos Palinurídeos, portanto piloto, nauta, guia. Embora com suas terríveis tenazes aterrorize a vista, fascina o paladar. (p. 993) 
* O telegrama é um trevo de papel dobrado que nos transmite notícias - as notícias! - frias, quentes, mornas, e normas, à distância. (p. 997)

* O lençol: uma espécie de toga essencial que nos cobre o corpo durante a operação noturna. (p. 998)

* A mesa, redonda ou quadrada, oval. Elemento básico de tangência e contaminação. Suporte conjuntivo ou adversativo da tribo. Festa fundamental; infesta às vezes. (p. 1000)

* O tomate é terrivelmente vermelho; tem tataporas; quanto mais vermelho mais inquieto, quase uma pessoa. Pertence à família das Solanáceas, portanto chama-se Solano. Resmunga. (p. 1003)

* O telefone é um objeto de metal, geralmente pintado de preto, geralmente redondo; uma boca sem corpo aderindo a uma e solicitando outra boca através do espaço. (p. 1008)

* O Uruguai é um belo país da América do Sul, limitado ao norte por Lautréamont, ao sul por Laforgue, a leste por Supervielle. (p. 1023)

* Algólidas (astron.) s. f. Tipo de estrela de curto período, que varia bruscamente de magnitude. (p. 1.026)

Num universo de 72 textos que compõem Poliedro, 13 possuem um ou dois parágrafos cujo torneio das frases é claramente decalcado de um verbete de dicionário. Mas esse molde é sempre subvertido por uma nota dissonante, seja através de advérbio, de adjetivo (categorias de palavras geralmente não usada na redação do verbete), de metáfora, de aliteração, de anagrama, de neologismo. O dicionário está presente, afinal "a função adâmica do poeta move-o a nomear as coisas e as pessoas" (p. 1.008), mas subvertido, confrontado, retorcido.

Esse intertexto com o dicionário, além da "função adâmica", mostra-nos dois outros aspectos do trabalho poético: 1) a pesquisa feita sobre o tema, o que caracteriza o poeta moderno como um estudioso, próximo a um cientista, e não apenas um inspirado, um possuído por forças sabe Deus de onde; 2) a explicitação dessa pesquisa e a conseqüente quebra da ilusão mimética. É como se o poeta franqueasse ao leitor a visão do laboratório, de seu processo criativo. Murilo Mendes não chega aonde Ponge chegou, não chega a publicar 
seus borrões, todas as variantes que deram o texto final (caso de Comment une figue de parole et pourquoi), mas aponta nesse sentido "seu dedo episcopal".

c) Neologismos - Se o intertexto com o dicionário revela o desejo do poeta de redefinir o mundo, a criação de neologismos dá um passo além, pois não se contenta em rearranjar palavras já existentes, mas em criar palavras novas - as que já existem são incapazes de dar conta da qualidade diferencial do objeto. Apesar de constar da Poética de Aristóteles ("Forjado é o nome ainda absolutamente não usado por ninguém, a que o poeta mesmo dá curso;") (s.d., p. 43), a formulação sistemática de neologismos é uma das marcas mais evidentes da literatura de vanguarda do século $\mathrm{XX}$, sendo seu paradigma James Joyce. O impacto provocado por esse procedimento depende da lingua em que é praticado. A inglesa, por não ser legislada, suportou-o com certa tolerância, apesar dos esperneios habituais dos catões de plantão. Já a francesa, controlada pela mão de ferro da Academia de Letras, tem uma intolerância jacobina para com o neologismo, a ponto de tal procedimento virar uma questão de política literária.

Francis Ponge, um antiacadêmico declarado, foi um dos poucos escritores franceses que ousou praticar o neologismo. Não com a ostentação joyceana, ou roseana, mesmo assim a ponto de merecer uma digressão de Philippes Sollers em seu ensaio "Francis Ponge ou la raison à plus haut prix." (ver PONGE, 1963, p. 51) A partir de Le Parti pris des choses, encontram-se neologismos, só que por não ser abundantes e ser em francês, o encontro do leitor com tal procedimento causa uma surpresa que não causaria num texto cuja marca mais evidente fosse justamente o neologismo. Seu uso parcimonioso tem o efeito da pedra entre caroços de feijão no poema de Cabral, ou seja, interrompe a "leitura flutual, fluviante" e faz com que o leitor volte, releia, se debruce ao menos sobre aquela passagem e reflita.

Tanto Antonio Candido (2000, p. 57-61), quanto Haroldo de Campos (1992, p. 75) chamaram a atenção para a prática deste procedimento em Murilo Mendes. Campos detecta o uso de neologismos na obra de Murilo a partir de Contemplação de Ouro Preto. Candido, comentando $A$ idade do serrote, vai mais além e demonstra o processo com que o poeta cria os neologismos, pondo o 
foco na utilização tanto de palavras, quanto da sintaxe adaptadas do italiano.

O ponto extremo do neologismo em Murilo se dá num poema em duas colunas paralelas que se encontra na terceira e última parte de Convergência, "Sintaxe", cujo título é "Palavras inventadas (em forma de tandem)" (p. 730). Aí o texto chega às bordas da incomunicabilidade. É o som das palavras que conta, e não seu sentido, ou seja, é um trabalho sobre o significante, não mais sobre o significado e menos ainda sobre o referente. Em outros poemas desse livro, também se encontram altas taxas de neologismo. Já em $A$ idade do serrote e Poliedro a comunicabilidade não é comprometida, pois, além da parcimônia com que o neologismo é usado, o discurso em que está inserido propicia sua compreensão.

Vejamos alguns neologismos significativos em Poliedro, livro que se encontra a meio caminho entre $A$ idade do serrote (tanto pela prosa, quanto por certas marcas memorialísticas recorrentes, como "quando menino" e "na minha infância") e Convergência (pela ousadia formal de certos textos):

"quadradoredonda" (p. 983); (p. 986); "trilemas" (p. 992); "capisquei" (p. 993); "disturbarva" (p. 999); "verdeveronese" (p. 1001); "amarelezas" (p. 1001); "irrespondia" (p. 1005); "infalha" (p. 1018); "amarelomem" (p. 1018); "ídola" (p. 1032); "miaular" (p. 1033); "desdorme" (p. 1035); "paralém" (p. 1035); "autochá"; "fantasticar" (p. 1036); "inpássaro" (p. 1036); "bipaga" (p. 1036); "orácula" (p. 1037); "inestrela" (p. 1041); "olhiver", "olhiverá", "olhiviu" (p. 1042); "plurissalas" (p. 1042); "infalam" (p. 1042); "autochina," "autoíndia", "autojerusalém", "autodelfos" (p. 1044); "flechadéia", "semidéia", "flechaidéia" (p. 1049).

O processo de criação de neologismos neste livro é basicamente:1) anteposição de um prefixo; 2) acoplagem de uma palavra à outra; 3) posposição de um sufixo; 4) feminização do substantivo masculino; 5) criação de verbo baseada no adjetivo; 6) aportuguesamento de verbo originário de outra língua. 
Estas "invenções vocabulares" ( $\mathrm{H}$. de Campos) ou "insólito lingüístico" (A. Candido) acrescem ao texto muriliano um grau a mais de estranheza. Ou seja, não são apenas as metáforas ousadas e inéditas que surpreendem o leitor, mas também o tecido significante e semântico que o levam a alterar seu campo perceptivo. Como é sabido, as crianças são férteis na formulação de neologismos, mas por ignorância ou excesso de lógica. Já um poeta culto adota tal procedimento pelo inconformismo perante o mundo legislado por dicionaristas e gramáticos. É mais um ato contra - que rege a poesia moderna.

d) Os jogos paronomásticos - Segundo Michèlle Aquien (1993, p. 205-206), "a paronomásia (do grego para, "ao lado de", e onoma, "nome") é uma figura que consiste em aproximar palavras de sonoridades análogas com sentidos diferentes [...]. Pode-se ainda chamar de "paronomásia in absentia" um fenômeno de paronomásia onde só figura na frase um elemento e onde o outro (e às vezes os outros) está ausente, mas é sugerido pelo contexto." Deve-se ainda acrescentar algo evidente: os jogos paronomásticos comportam a aliteração, a rima e a homonímia. Mais usados comumente em verso, eles freqüentam a prosa dos poetas e dos prosadores mais ousados que valorizam não só o significado da sentença, mas também o significante, enxertando na prosa sonoridades mais encontradas em verso. A paronomásia é também uma das bases do trocadilho, procedimento cassado pelo "bom gosto" oficial das letras em língua portuguesa, talvez por ser uma das mais eficientes formas de aproximar o discurso escrito do oral (a linguagem popular é rica em jogos paronomásticos construídos inconscientemente), e essa aproximação só começou a ser bem-vinda a partir do Modernismo.

Murilo Mendes, em sua prosa européia, usa tal procedimento com uma freqüência muito pouco encontrável nos outros grandes autores da literatura brasileira, seus contemporâneos - tanto em verso quanto em prosa. Jogar com a paronomásia dá a seu texto um humor raro, que para uma mente sisuda e dogmática pode parecer infantilismo. E é exatamente este piscar de olho ao ludismo infantil que cria no texto muriliano uma atmosfera docemente dissonante. Mais uma vez recorreremos a Poliedro para uma amostragem significativa de tal procedimento (as palavras em situação paronomástica virão em itálico): 
* ["A Baleia"] "Reina soberana, sem vizinho ou confronto, sobre os mares e os mores, excluindo-se voluntariamente da carta das rações." (p. 983)

* ["O Copo"] "O copo no corpo. O copo na copa. O copo cupo. O copo ácopo.

O copo-de-leite no copo.

A vibração do copo. A viração do copo. A vidração do copo. A vinhação do copo.

O copo toca piano atento ao copo. O copo sem testo, sem texto." (p. 998).

* ["A gravata"] "Gravata ou gravatá? Por meu gosto poderão perfeitamente coexistir." (p. 999)

* ["Frutas da infância e Post"] "Os uivos da uvaia. A raiva da cabeluda. A força da banana. O ácido do araçá.

[...]

A odre podre de qualquer fruta.

$[\ldots]$

O sumo do universo, o saber do sabor, o sabor do saber". (p. 1000-1001)

* ["Palmeiras"] "As palmeiras da república dos Palmares, palmas a Ganga Zumbi.

Dou a mão à palmatória: as palmeiras naturais ou têxteis são belas, convém à Ode.

Um corpo de mar com um rabo de palmeiras, Rabat, Rodes ou Recife.

PALMES! Mallarmé." (p. 1001)

* ["O Tomate"] "Examino o tomate com uma lente, lentamente, o tomate quente, naturalmente. Vejo um animal minúsculo agarrado-lhe à pele, um espião. Mas a lente mente? Fico tatibitate diante do tomate (Ou tomarte, vermelho que nem Marte). Um crítico de arte diante do tomate. (...)

Como se vê o tomate ainda pensa em brilhar. Sem nenhum tato. Mas agora ei-lo tatibitate, resfriado, quase branco. Torto, tonto. Nada mais que um ex-tomate, vítima da lente (lenta) de um crítico de arte sem tirte nem guarte." (p. 1004)

* ["A Luva"] (Já vimos acima)

* ["O Menino experimental"] "O menino experimental confessase ateu è à-toa." (p. 1003). 
* ["As Lanças"] "As lanças de Mallarmé. As lanças de Velázquez. Os dados do poeta. Os dedos do pintor." (p. 1016) * ["O Trovão"] "E dizer-se que antigamente o trovador chamava-se também trovão, de trova! Não creio que os trovadores trovejassem." (...)

(...) áspero hóspede (...)" (p. 1022)

* ["Dores do Indaiá"] “(...) supunha-a sardenta, sedutora, e segundo meu pai - um tanto solerte e sinuosa, iaiá.” (p. 1023)

* ["Algólida"] "(...) algólida de submergidas Argólidas, quem te viu e agora quem te vê durante as noites de - segundo Rimbaud - mecânica amorosa?

Quem te viu e agora, algólida, quem te vê, se és brusca e variável; se imprevista cambias de atitude, altitude e magnitude, com teus olhos de rainha-cláudia, raivosa no teu chapéu de vento; (...) (p. 1026-1027).

*["Setor Texto Délfico"] "Passarei. Sobrevoado pelo mito, o espanto, o in-pássaro no impasse, o cosmonauta, o céu planificador. (p. 1036)

"As "almas" pelo faro sem farol chegam ao paralém." (p. 1037)

"As tesouras de Átropos definidoras definitivas desconhecem a história." (p. 1037)

(...)"ubiqua Tubingue" (...); "tantos tântalos" (...); "fechaduras de caras fechadas (...)" (p. 1039)

“(...) No microcosmo, ainda tipográfico, do macrocosmo topográfico." (p. 1040)

"O astro gizado, calculado, pintado, fotografado, odeado, odiado, amado, desembarcado - fichado, mesmo assim sangrando te acena ao longo da tua cena, Delfos." (p. 1040)

"O grande oliveiral olhiverá? já que olhiviu, a paz." (p. 1042)

"O rato é rei nas roupas do rei." (p. 1040)

"Reverteremos ao ovo, ao osso, ao horto antigo, às estrelas esferóides, ao átomo-caverna, ao texto total que gira sobre si mesmo. Ao T." (p. 1047)

"Os gritos electrônicos de Electra." (p. 1048)

"Aristóteles Platão pássaros possantes polêmicos paralelos contrastantes inquietantes oficinas volantes passai passai não passeis parai liberai os pontos de interrogação parai o passo a página tocai-vos nunca mais nunca mais me encontrareis a 
outros voltareis para o passo a página a outros instruireis a outros legareis o trabalhado canto.

Além do além além do paralém alô dupla flecha alada voa além do álamo, da lâmpada, além de Alá, além de Elêusis... além de Belém além de Belém do Pará além de Delfos o movimento alado alódola tangendo os deuses para além dos deuses amém e além do amém anti-Zênoa de Eléia a flechadéia a pura semidéia a flechaidéia voa amém além do amém, do santiâmen ou do santiamém, âmem além do amar além do paralém além do amém, âmem." (p. 1048-1049).

Francis Ponge, desde Le parti pris des choses até seus últimos textos, recorre constantemente aos jogos paronomásticos, ao contrário de Murilo Mendes, que intensifica seu uso apenas a partir da fase européia. O emprego intensivo da paronomásia não deixa de ser um rompimento com os princípios do poema em prosa, esboçados por Baudelaire (1973, p. 22) no prefácio de Petis poèmes em Prose (Spleen de Paris), onde não haveria ritmo nem rima. Ora, o que F.P. e M.M. fazem é justamente o inverso. E esse procedimento confunde as fronteiras entre os gêneros ou funda um outro, a "proesia".

e) A materialidade da linguagem - Desde seus primeiros textos, Francis Ponge demonstrou interesse pelo aspecto físico, material, da linguagem. Para ele, a linguagem não era apenas um código de signos capaz de registrar uma idéia, um sentimento, um conceito, mas também um corpo, com a forma inerente a todo corpo. Em "La promenade dans nos serres" (O passeio por nossas serras), de Proêmes, um texto escrito em 1919, quando o poeta contava apenas 20 anos, as letras e as palavras são tratadas como seres físicos capazes de salvar "o homem que não sabe mais dançar". Ele continuará durante toda sua carreira a empregar as letras, os acentos, as sílabas e as palavras, seja como comparantes, seja como comparados. O livro Pièces está pontilhado deste procedimento. Em "14 juillet" (14 de julho) os números e as letras do título servem para ilustrar os objetos que os franceses utilizavam para festejar a data: o 1 é uma lança, o 4 uma bandeira desfraldada. A estrutura do "grenier" (celeiro), no poema homônimo, tem forma de A. Em "Le paysage" (A paisagem), "O horizonte, sublinhado de acentos vaporosos, parece escrito em pequenas letras, de uma tinta mais ou menos pálida segundo os jogos 
de luzes." Em "Le lezard" (A lagartixa), a superfície cintilante da rocha parece com uma página. Encontra-se ainda tal procedimento em "L'Anthracite" (A Antracite), "La cruche" (A Moringa), "Les olives" (As azeitonas) e em "La chèvre" (A cabra).

Sabe-se que Ponge escrevia, durante os anos 20, com o alfabeto pregado na parede e o dicionário Littré ao lado. Em seus textos mais teóricos, como alguns de Méthodes, ele aborda a materialidade da linguagem e enfatiza o aspecto tipográfico da literatura. Para Ponge, no século XX, a literatura é mais uma questão visual que auditiva: "praticamente as noções de literatura e tipografia se confundem" (1999, p. 641). Toda esta importância dada ao aspecto visual do texto é derivada do princípio de que "as palavras são um mundo concreto, tão denso, tão existente quanto o mundo exterior" (PONGE, 1999, p. 675).

Murilo Mendes, ao "francisponjar-se", também levará em conta o lado físico, "táctil" da linguagem, chegando a intitular dois poemas de Convergência de "Estudos da letra V" e "O erre". Haroldo de Campos (1992, p. 65) vê o prenúncio dessa importância dada à materialidade da linguagem num aforismo contido em $O$ discípulo de Emaús: "Passaremos do mundo adjetivo para o mundo substantivo". Mas será nos três livros aqui abordados onde este procedimento alcançará um lugar de destaque. Não surpreende que esta maneira de lidar com a linguagem seja concomitante ao fato de tratar de objetos, de centrar o olhar sobre pequenas coisas. A letra $V$ ou a letra $R$ podem suscitar imagens, podem ser vistas com tantos significados possíveis quanto o ovo ou a vassoura. Não há mais temas transcendentes, abstratos, metafísicos, em qualquer lugar pode haver poesia, até (ou sobretudo) na matéria que a compõe: "O menino experimental não anda nas nuvens. Sabe escolher seus objetos. Adora a corda, o revólver, a tesoura, o martelo, o serrote, a torquês. Dança com eles. Conversa-os" (p. 1013).

Em Poliedro, a pérola é comparada a "uma vírgula luminosa" (p. 997). "O Rubicão" (p. 1024) tem a seguinte passagem: "Decompondo a palavra, temos rubi-cão. Trata-se certamente de um cérbero, poderoso porteiro que guardava um rubi ou raríssimo diamante do outro lado do riacho [...]", onde a separação arbitrária das sílabas, criando duas novas palavras, leva o poeta a uma dedução etimológica fantasista. Em "Marruzko" (p. 905), de A idade do 
serrote, há um parágrafo significativo: "O nome do leão era Marruzko. Esses dois erres, com o zê azedo e o ka cortante, mais o urro do u no centro, formavam um composto que me aterrorizava". "Grafito segundo Kafka" (p. 648), de Convergência, possui uma passagem muito próxima a esta: "Os dois $\mathrm{K}$ do meu nome: num só nome./ O F comprimido entre A, dois K./ Pobre deste nome sem esfera. Só ângulo". "Murilograma a Guido Cavalcanti"(p. 667-668), do mesmo livro, começa com "Radiograficamente entrego-te o texto táctil/ Interrogo o que / sem transístor / vês apalpas ouves/ [...]" e mais adiante : "No esdrúxulo território tipográfico/ Atravessado pela espada do teu nome/[...]". "Murilograma a Nani Balestrini" (p. 699700) contém duas estrofes onde a materialidade do poema é tratada: "Que é finalmente o poema:/ palavra ou frase? Sem frase levanta-se a palavra?// O poeta planifica/ O texto de linhas retas./ Não o que o texto quer". Em um aforismo de "Setor texto délfico", de Poliedro, essa postura materialista diante da linguagem é fundamentada: 1) "Cada um descubra sua alçapema. Sua turbina. Saiba parafusar e desparafusar sua lira." (p. 1043), onde o verbo "parafusar" dá um sentido mecânico, material, à lida com a linguagem. Em "Momentos e frases" (p. 924-925), de A idade do serrote, "as pessoas são frases"; em "Primo Nélson"(p. 926): "Excetuando moças e meninas, não achava coisa tão bela quanto letra de fôrma."; em "A Rua Halfield" (p. 960), há "olhos em itálico". Na quarta parte de "Texto de consulta" (p. 737-740), que fecha Convergência, lê-se: "A palavra nasce-me/ fere$\mathrm{me} / \mathrm{mata}-\mathrm{me} / \mathrm{coisa}-\mathrm{me} /$ ressuscita-me". E na nona e última parte: "O texto-coisa me espia/ Com o olho de outrem".

Gérard Genette (1976), em Mimologiques, nomeia esta postura diante da linguagem que têm os dois poetas, de "grafismo", um tipo de "cratilismo primário" (em que os signos são motivados e não-arbitrários, como queria Saussure). Tal postura do poeta diante da linguagem é tão antiga, ou mais, quanto o diálogo de Platão, Crátilo. Sua retomada por dois poetas modernos é mais uma confirmação de que "Qualquer que seja a forma da sociedade futura, nunca mais escaparemos a esses gregos” (M.M., p. 1042).

A mudança para Roma (o coração do Cristianismo), uma viagem à Grécia e a freqüentação dos textos de Ponge levaram Murilo Mendes a aguçar esta tendência que se encontra em germe nos livros de versos escritos ainda no Brasil, como em Poemas: "Meu 
pensamento esbarra nos seios, nas coxas e ancas das mulheres,/ Pronto." (p. 106); em O visionário: "Este poema não é teu/É da tinta e do papel." (p. 207); em A poesia em pânico: "A matéria é forte e absoluta/ Sem ela não há poesia" (p. 297); em Metamorfoses : "Sim: letra e nuvem/ lutam com os sonhos/ Pela posse do poema" (p. 370); em Poesia liberdade: "O poema olha para mim, e, fascinado, me compõe" (p. 434). Seu apego, desde jovem, às artes plásticas talvez seja uma sensata pista para compreender a ênfase dada ao lado... plástico da linguagem. Em "Carta aos chineses", texto que fecha "Setor palavra circular", em Poliedro, vemos: "Esse alfabeto e essa caligrafia vos ensinavam a pensar com as coisas, segundo nos aconselha G.F.W. Hegel, um grande mestre do Ocidente (e por que não também do Oriente?)" (p. 1032). É provável, pois, que o poeta tenha acatado o conselho hegeliano e posto, entre as coisas, a linguagem.

f) A metalinguagem - Todos estes procedimentos de linguagem vistos até aqui, de uma maneira ou de outra, fazem parte do que é chamado, depois de Jakobson, de metalinguagem, ou seja, o discurso sobre o código. Pode-se dizer que toda uma linhagem de poetas que parte de Mallarmé, e a que pertencem Ponge e Murilo, realça, em suas obras, o trabalho sobre a linguagem. Eles tomaram como princípio a célebre frase de Mallarmé a Degas: "Não é com idéias que se fazem versos... É com palavras".

Essa reflexão, essa crítica, essa dobra da linguagem sobre si mesma foram postas em marcha pelos poetas, grosso modo, em quatro níveis: 1) quando o texto comenta a linguagem da poesia em geral ou de um autor em particular. Tal procedimento é classificado por Claudette Oriol-Boyer (1989, p. 111-112) como "metatextual denotativo"; 2) quando o texto se comenta, o que a autora chama "endometatextual denotativo"; 3) quando um texto utiliza um objeto, à guisa de espelho, para comentar-se. Isso acorre quando o poeta imbrica a linguagem-objeto, definida por Jakobson (s.d., p. 127) como a linguagem que fala de objetos, e a metalinguagem, que fala da linguagem; e 4) a adequação da linguagem ao objeto escolhido como tema do texto - uma formulação de Ponge.

O metatextual denotativo se encontra em abundância na obra dos dois poetas. Em Ponge, por exemplo, particularmente nos textos 
de Méthodes, como "My creative method", "Le Murmure", "Le dispositif Maldoror-Poésies", "Proclamation et petit four", Réponse à une enquête sur la diction poétique" e "Tentative orale". Nesses textos, há tanto uma reflexão sobre a literatura (sobre a poesia em particular), quanto comentários sobre outros escritores. Mesmo em seus textos, digamos, mais poéticos, como "Notes prises pour um oiseau", de La rage de l'expression, há comentário sobre um outro texto. Mas o grande livro de Ponge, onde se encontra o nível do metatextual denotativo assim como os três outros níveis, é Pour um Malherbe - sua arte poética. Quanto a Murilo Mendes, podem ser classificados no nível estritamente metetextual denotativo suas contribuições de crítica literária para jornais e revistas, alguns "murilogramas" e "grafitos" de Convergência e boa parte dos textos de Retratos-Relâmpago.

O endometatextual denotativo (quando o texto se comenta, dobra-se sobre si mesmo) é outro nível de metalinguagem freqüente na poesia moderna. Ponge e Murilo não foram diferentes, mesmo que não tenham abusado e tornado todo poema um poema sobre o poema, como sói acontecer a aprendizes de feiticeiro. Textos como "Les mûres" ("As amoras"), de Le parti pris des choses, e "Notes prises " pour un l'oiseau" são provas deste procedimento na obra pongiana; "Murilograma a Nani Balestrini" e "Texto de consulta", ambos de Convergência, seriam o equivalente na obra muriliana.

A linguagem-objeto imbricada à metalinguagem consiste em, escrevendo sobre um objeto, ao mesmo tempo, escrever sobre a linguagem. Essa é uma atitude lógica para quem a linguagem é "La figue (sèche)" [O figo (seco)] e "De la nature morte et de Chardin" (Da natureza morta e de Chardin), os dois escolhidos por Gleize para constar de seu repertório de textos críticos sobre a poesia.
No segundo texto, por exemplo, Ponge utiliza um objeto, no caso os quadros de Chardin, como espelho de sua escritura. O que é dito dos quadros poderia ser dito perfeitamente de seus textos - é como o que diz João Cabral de Manolete em "Alguns toureiros".

Em Murilo, há uma seqüência de três textos em Poliedro onde se encontra essa relação especular entre o objeto e a linguagem utilizada para tratá-lo; "Estilhaços", onde curtos parágrafos abordam o objeto sobre vários ângulos (estilhaços), começa com: "Detesto 
estilhaços. Quando irrompem de qualquer parte, atacam-me a pele, a vista, os ouvidos, a planificação do texto; sournois" (p. 996). Com efeito, o texto atacado será estilhaçado, pois nele, apesar da brevidade, são encontrados: 1) uma metáfora escatológica de grande impacto: "São merdinhas de diamante a gritar."; 2) logo sucedida (no parágrafo seguinte, precedido por uma bola preta que separa os três blocos do texto) por uma tirada de humor sádico: "Eu ofereceria a uma nazista (mas felizmente não conheço nenhuma) um colar de estilhaços de vidro giratórios, movidos por um dispositivo mecânico especial, o que permitiria roer-lhe o pescoço dia e noite."; o texto salta bruscamente, deste para o parágrafo seguinte, de um instrumento de tortura para um hipotético e prosaico pregão de camelô: "Colares de estilhaços de vidro! Olhem os lindos colares...". "Estilhaços" finda, em uma nova guinada abrupta e angulosa, com a convocação da alta literatura: "Escapou a Dante mais esta oportunidade de aumentar seu Livro: fazer servir a certos criminosos uma salada de estilhaços de vidro".

Depois de "Estilhaços", vem "Pérola" (p. 996-997), curto, com apenas um parágrafo, fechado em si, redondo como... uma pérola:

Os dedos da natureza extraem a pérola duma concha bivalve: delicadíssima operação cesariana. E gostariam de oferecê-la diretamente à mulher; mas têm que passar pela manopla do negociante, essa grande potência corrosiva. A pérola é uma minúscula sílfide japonesa; pérola, o casulo do silêncio, uma vírgula luminosa, a perfeição do zero, o eco da pérola.

O terceiro e último texto da seqüência, "O Telegrama" (p. 997), o maior dos três, é entrecortado por... quatro telegramas: o primeiro assinado por Charles Baudelaire, o segundo por Murilo Mendes, o terceiro por uma mãe juiz-forana e o último por Safo. Vale lembrar que este é um dos mais divertidos textos murilianos, o que contrasta com a sobriedade de "Pérola" e mais ainda com a gravidade de "Estilhaços".

O último nível metalingüístico arrolado aqui, a adequação da linguagem ao objeto, começa a ser formulado por Ponge num texto datado de 1928-1929, "Raisons de vivre heureux" ("Razões de viver feliz") e publicado em Proêmes: "[...] é preciso não uma retórica por 
autor, mas uma retórica por poema" (1999, p. 198). Essa fórmula será amadurecida, aperfeiçoada, reiterada nos textos dos anos 50 publicados em Méthodes. Como demonstração desse procedimento, vejamos um texto de cada poeta, ambos com o mesmo título: "As andorinhas".

O título do poema de Ponge consiste já num comentário sobre o que se lerá em "Les hirondelles ou dans le style des hirondelles" (1999, p. 795) ("As andorinhas ou no estilo das andorinhas"). Seus seis primeiros curtos parágrafos mimetizam a maneira de voar das andorinhas, num poema cheio de "reviravoltas agudas", "acelerações, retomadas" e classificado, no próprio corpo do texto, de "bizarro". Murilo Mendes, por sua vez, adota o mesmo procedimento, mas seu texto é bem mais curto do que o de Ponge, que se estende ao longo de cinco páginas no volume 1 da Pléiade. "As andorinhas" faz parte de Convergência, mas poderia encontrar-se no "Setor microzôo", de Poliedro, ou ainda $\mathrm{Na}$ Idade do serrote, pela invocação à memória, mais um indício de que esses três livros, além de contemporâneos, possuem peças intercambiáveis por guardarem um sema em comum a invenção de linguagem:

As andorinhas giram miram viram, piam piadas, microfilmam a nuvem, sobrevoam casos, sobrevoam casas, quebram fios, quebram copos, falam mal de mim, falam mal de mim. Não existe mam, não existe mem, não existe mom, não existe mum. Portanto elas falam mal de mim. Giram, miram, piram.

As an-dorinhas: na minha infância houve uma Dorinha quase sem peitos, mas cheirava bem. Quebrava sempre copos.

O céu é adorável, andorinhável, andorável, acoplável com terra, inquebrável.

Dito pisano: "Per l'Annunziata la rondine è arrivata; e se non è arrivata è per strada o è malata".

curtos e veloze "Hirondelles", "As andorinhas", além de parágrafos repetições, decomposição de palavras quenomásticos, neologismos, popular etc. Murilo concentra onde Ponge formam outras, apelo a dito da loção pongiana. 
g) O Humor ou a alegria de fazer - Existe em ambas as obras um júbilo da escrita. Apesar de leitores de Baudelaire (mas qual o poeta que se preza não o é?), nem Ponge, nem Murilo incorporam a maldição de serem poetas. ${ }^{3}$ Em conseqüência dessa postura diante da vocação, seus textos, mesmo que muitos deles possuam gravidade, a compensam com o emprego contumaz do humor. Segundo Bergez, Géraud e Robrieux,

O humor busca o insólito, a surpresa, e participa do jogo: ele zomba da pertinência ordinária da mensagem endereçada a um destinatário. Se a mensagem humorística aparece a princípio como impertinente, ela obriga a inteligência a superar esta primeira reação para descobrir uma pertinência secundária. É, portanto, em sua impertinência pertinente que se reconhecerá o humor. (1994, p. 111)

A "impertinência pertinente" de Francis Ponge seria de dois gumes: 1) o repertório temático que ele criou, muito distante daquele da poesia oficial, deriva dos nobres sentimentos, das grandes interrogações e das grandes causas humanitárias. Ponge, ao alijar o Homem e o Amor de sua poética, torna-se "impertinente" e sua pertinência só será captada num segundo momento; 2) a linguagem adotada para abordar temas "não- poéticos", linguagem que, ao se dizer não poética, alcança lugares até então desconhecidos. "Escargots" (caramujos, ou "aruás", como preferiu João Cabral, em "As formas do nu"), por exemplo, "são o terror das alfaces" e; onde quer que se encontrem, podem "entrar em casa e desafiar os importunos". "La crevette" (o camarão) tem muitos "órgãos de circunspecção" que o farão se perder. "La grenouille" (a rã) é uma "anã anfíbia", "uma Orfélia manca", uma "nervosa" que tem "bonitas pernas", seus "músculos longos são de uma elegância nem carne nem peixe". "Le lézard" (a lagartixa) é "uma obra-prima pré-histórica, de um metal entre o bronze verde e a prata viva", é "chic". Todos os textos de Ponge sobre animais são carregados de humor porque a

3 Ver o poema "Bénédiction" (Bênção), em Les fleurs du mal (As flores do mal). Tradução Ivan Junqueira. Rio de Janeiro: Nova Fronteira, 1985, p. 104-105. 
abordagem feita é uma combinação de redação escolar com relatório científico, porém com uma carga metafórica e paronomástica vertiginosa e é justamente esta "impertinência" (a metáfora e a paronomásia em um lugar a princípio inapropriado: a redação escolar e o relatório científico) a fonte mais perceptível de seu humor.

Quanto à alegria de fazer, talvez mais adequado, em vez de alegria, no caso de Ponge, seria dizer a gana ("la rage"), ou seja, a vitalidade escritural, o esforço extraordinário para colher a qualidade diferencial do objeto (do que ainda não foi dito sobre ele, se é que alguém antes de Ponge teria olhado pelo viés da poesia para uma máquina de lavar, um limpa-fossa, uma azeitona, e outras "insignificâncias"). Seu livro intitulado la rage de l'expression é exatamente a demonstração deste princípio: o texto não é um artefato acabado, polido, parnasiano, apenas a fórmula perfeita sobre um objeto. O texto seria antes a demonstração do esforço do poeta em descrever o objeto: os tateios, as tentativas fracassadas, as repetições, até que a fórmula seja alcançada. Ao expor os bastidores da criação textual para os leitores, Ponge funda um novo gênero feito ao mesmo tempo de soma e subtração. Ele soma (ao incluir as variantes) e subtrai (os segredos e macetes da criação).

O humor da fase européia de Murilo Mendes guarda semelhanças com o de Ponge. Os jogos paronomásticos e os neologismos (que muitas vezes vêm juntos) são uma das fontes do humor em ambos porque, nesses dois procedimentos, a pertinência só se revela num segundo tempo, após a reconfiguração perceptiva operada pelo leitor. $A$ idade do serrote e Poliedro estão polvilhados de passagens com esse teor. No primeiro livro, o humor se revela pela disparidade (a impertinência) que há entre a visão do menino (ou do louco) e a visão do adulto. No segundo, sobretudo nos textos sobre animais ("Setor microzôo"), é onde o humor ocorre com mais freqüência, por motivos semelhantes aos de Ponge - a combinação de redação escolar com texto científico carregado de metáforas e jogos " paronomásticos. Além disso, Murilo recorre a anedota [uma aluna, "Giovana T..." (p. 1027), que mistura os pontos da história da literatura brasileira, numa espécie de samba do crioulo doido], a deslocamentos atributivos [em "O ladrão católico" (p. 1028), a "capa é melancólica", o pensamento é "de duas cabeças" e apóia-se nas "árvores absurdas do jardim"]. Em "As núpcias falhas" (p. 1029), o 
humor surge na primeira linha por um complemento inusitado (impertinente) a um sintagma: "Catarina comia bife a cavalo, eu comia bife a pé."

Esse humor muriliano seria em decorrência talvez da "alegria de fazer", que ele atribuiu a Braque e que poderia ter atribuído a si. Há uma afirmação peremptória em "Primo Nélson", de $A$ idade do serrote, que corrobora essa suposição: "Tinha uma intuição obscura de que estava destinado mesmo a ser escritor. Agora que é moda entre tantos escritores esnobar a literatura, continuo a fazer profissão de fé literária. Afronto mesmo o ridículo do pejorativo: fui e sou literato desde o ventre da minha mãe" (p. 926).

Essa "profissão de fé" na literatura se divisa com "a gana da expressão" de Ponge. Escrever, para ambos, não foi uma doença nem uma maldição (nem foi jamais um meio de vida, pois se sustentaram com atividades paralelas), mas uma vocação aceita e jamais negada, também jamais dramatizada em termos piegas diante das dificuldades inerentes a tal postura. No "retrato-relâmpago" de Braque (p. 1253), Murilo conta o encontro do pintor com Chaplin em Saint-Paul de Vence : "sorriam, um em francês, outro em inglês; mas o prazer dos dois falava a mesma língua". Talvez seja o caso do próprio Murilo e de Ponge.

\section{Ainda algumas semelhanças}

Além de temas e procedimentos de linguagem em comum, cujos principais acabamos de ver, Murilo Mendes e Francis Ponge possuem outros pontos de contato, como certos princípios estéticos, amigos e dados biográficos.

O primeiro ponto a chamar a atenção de um leitor atento de ambos é o senso de proporcionalidade, ou seja, o lugar do homem no universo em relação a Deus (Murilo) e às coisas (Ponge). $\mathrm{O}$ humanismo de ambos é controlado, tem seus limites metafísicos (em Murilo) e físicos (em Ponge). A crença nas ciências positivas, herdada dos grandes sistemas filosóficos do século XVIII, da Revolução Industrial, da Revolução Francesa, desaguou na carnificina das duas guerras européias do século XX, de que os dois poetas foram contemporâneos - o brasileiro as acompanhou de longe (o que não evitou de deixar marcas profundas em sua poesia), o francês 
participou das duas. Portanto, esse controle do humanismo é visível nas duas obras, tanto de maneira velada, quanto desvelada.

Esse senso de medida, de proporção, este desejo de pôr o homem em seu devido lugar é perceptível em Ponge desde Le parti pris des choses, sobretudo em "Notes pour un coquillage"(1999, p. 40) ("Notas para uma concha"), cujo trecho a seguir não poderia ser mais claro:

Não sei por que desejaria que o homem, em lugar desses imensos monumentos que só demonstram a desproporção grotesca de sua imaginação e de seu corpo (ou então de seus ignóbeis costumes sociais, corporativos), em lugar ainda dessas estátuas em sua escala ou ligeiramente maiores (penso no David de Michelângelo) que são só simples representações, esculpisse espécies de nichos, de conchas para seu tamanho, coisas muito diferentes de sua forma de molusco no entanto proporcionadas a ele (as choças negras me satisfazem bastante desse ponto de vista), que o homem tratasse de criar às gerações uma morada não muito maior que seu corpo, que toda sua imaginação, suas razões estivessem ali compreendidas, que empregasse seu gênio à justeza, não à desproporção, ou, ao menos, que o gênio reconhecesse os limites do corpo que o suporta.

Mesmo na segunda fase de sua obra, aquela onde o poema em prosa é substituído pelo canteiro de obras do texto, que poderia ser lida como sinal de desmesura, Ponge irá defender este princípio de proporção, de justeza. Murilo, tomando como paradigma Deus, ou Mas o oposto de Ponge, chega a resultados (e princípios) semelhantes. Mas na fase européia, será um bicho que lhe dará a noção dos limites, não só do espaço, mas também do tempo. Eis os três primeiros parágrafos de "A preguiça" (p. 990-991):

Muito cedo descobri, naturalmente, o bicho-preguiça, maravilhando-me com seus ademanes. Foi mais tarde, em plena juventude, que revisitando a preguiça no Jardim Zoológico do Rio tive a revelação de sua importância: deu-me de repente, mal sabe ela, a idéia do nosso limite no tempo e no espaço. 
Com efeito vi a preguiça mover-se em câmara lenta, passando com dificuldade, sempre de olhos baixos, de um galho para outro: limitada concretamente, visivelmente, pelo tempo. E via-a passar de um galho a outro, voltando, depois de muito magicar, àquele galho inicial: sim, limitada no espaço. Dupla operação resolvendo-se numa só.

A preguiça foi encarregada peles deuses didáticos de, não digo destruir, mas corrigir a noção que eu possuía do infinito. Tal noção tinha me sido transmitida pelos livros de Victor Hugo, hélas! Agiu portanto, já era tempo, como um dispositivo anti-hugoano, anti-hiperbólico, funcionando em campo de manobras do conhecimento. E sem matar ninguém.

O restante do texto será um jogo entre citações (de Pascal, Ortega y Gasset, Quevedo e Mallarmé), decalque de dicionário e a lição aprendida da preguiça, num andamento tout à fait pongiano.

Outro ponto de contato entre os dois poetas é a recorrência (admirativa) a poetas como Rimbaud, Lautréamont e Mallarmé - que ora são citados, ora comentados. É como se ambos partissem de um mesmo tronco e cujos laços familiares (as afinidades eletivas) continuassem sendo exercidas por conhecidos em comum, como o filósofo alemão Max Bense, os poetas Haroldo de Campos e Giuseppe Ungaretti, que foi traduzido para o francês por Ponge e traduziu Murilo para o italiano, formando uma rede, "um tecido" (os inimigos chamariam uma máfia) cujos nós se dão pelo apreço às vanguardas e pela prática de certos princípios, como o experimento formal e o materialismo da linguagem.

As biografias de ambos também guardam semelhanças: foram professores em idade já madura, escreveram para catálogos de exposições de artistas plásticos e, pela amizade que tiveram com estes, formaram um acervo valioso e significativo com alguns dos principais nomes da pintura do século XX. Estes textos foram reunidos em livros: L'Atelier Contemporain (F.P.) e A Invenção do Finito (M.M.). E na obra de cada um o diálogo com as artes plásticas é uma constante. 


\section{Diferenças significativas}

Recorrendo a uma imagem, pode-se dizer que as semelhanças entre dois autores seriam pequenas ilhas num oceano de diferenças e, ao divisar ao largo ou em sobrevôo o panorama, o olhar incidirá por mais tempo justamente nas ilhas, como recurso à monotonia das águas. Mas mesmo as águas em sua monótona mesmice possuem certas manchas, causadas pelas correntes ou formação do solo, que atraem um olhar acurado. Um estudo comparativo entre as obras de Francis Ponge e Murilo Mendes não poderia omitir, sob pena de ter sua validade contestada pelo emprego abusivo da arbitrariedade, as diferenças significativas entre as duas, diferenças que, em vez de negar as semelhanças, ajudam a iluminá-las, esclarecê-las.

A primeira diferença significativa entre os dois poetas é a língua em que cada um escreveu. O português do Brasil possui uma flexibilidade normativa (a ponto de haver uma norma portuguesa e outra brasileira) que o francês não tem. Por conseguinte, uma quebra da norma produz muito mais escândalo em francês do que em português, daí os neologismos e arcaísmos serem usados com bem mais moderação por Ponge e mesmo assim provocar um choque num leitor francês, ao passo que os mesmos procedimentos em Murilo são aceitos com mais tolerância, posto que os pioneiros do Modernismo já tinham arrombado o cofre-forte da "sintaxe lusitana", e a linguagem criativa e contra-a-norma tinha ganho um certo status de normatização a partir dos anos 30 .

Outro ponto significativo que distancia as duas obras é o verso. Grande parte da obra de Murilo, sobretudo de sua fase brasileira, foi escrita em verso. É verdade que em versos polimétricos e sem rimas (exceto Sonetos brancos, mesmo assim sem rimas, como diz o título). Já na obra de Ponge, os poemas em verso são ocasionais e muitas vezes, quando ocorrem, estão inseridos num longo textocanteiro, cercados de prosa por todos os lados. Nesse quesito, ambos seguiram o eixo principal das poéticas das respectivas línguas: a grande poesia francesa do século XX foi escrita em prosa (Saint-John Perse, Henry Michaux, René Char etc.), enquanto a grande poesia em português foi escrita em verso (Fernando Pessoa, Manuel Bandeira, Carlos Drummond de Andrade, João Cabral de Melo Neto, etc). 
O Surrealismo é outro nódulo de discórdia entre os dois. É arqui-sabida a adoção por parte de Murilo de vários princípios surrealistas (principalmente em sua fase brasileira), enquanto Ponge, contemporâneo e conterrâneo dos surrealistas, escreveu, formalmente, contra o Surrealismo, mesmo que tenha se solidarizado politicamente com Breton. Nesse aspecto, uma aproximação da obra de Murilo com a de Michaux (a quem é dedicado "O emigrante", poema que abre $A s$ metamorfoses, e de quem um "retrato-relâmpago" é traçado, fora o fato de tê-lo conhecido pessoalmente) teria uma pertinência bem maior do que com a de Ponge.

Por último, e talvez regendo a anterior, a questão religiosa. $\mathrm{O}$ catolicismo de Murilo se posiciona diametralmente ao ateísmo pongiano. Se não fosse isso, seria ainda o protestantismo de origem familiar. Deus e a Igreja católica são fustigados intermitentemente nos textos pongianos. Quanto a Murilo, mesmo com sua aproximação da cultura grega e a tentativa de conciliar cristianismo e paganismo em "Setor texto délfico", além das críticas que fez à Igreja católica a ponto de D. Marcos Barbosa (Ver CORREIA DE ARAÚJO, 2000, $\mathrm{p}$. 222-223) se recusar a participar de um evento em sua homenagem, foi ele até o fim da vida e da obra um crente, mesmo que o tom religioso tenha sido mitigado em sua fase européia.

O que viemos de fazer, comparando uma fase da obra de Murilo Mendes [que José Guilherme Merquior denomina de "poética paronomásica"(in MENDES, 1995, p. 18)] à de Francis Ponge, foi bem sintetizado, em outro contexto, por Flávio R. Kothe, para quem

A literatura comparada não é a simples comparação literária: decodifica um processo, em que determinado
texto, com grau maior ou menor de identidade em relação a outro(s) texto(s), delimita e define a sua identidade por suas diferenças quanto a ele(s). Carrega $\mathrm{cm} \mathrm{si}$, portanto, identidades e diferenciações. O trabalho comparatista faz o mapeamento disso, tentando descobrir as leis e os sentidos que presidem as mulações. (2002, p. 385)

A aproximação, portanto, de duas obras tem, antes de tudo, a função de livrar o leitor do absoluto. Se, como vimos no início deste trabalho, a comparação é uma das operações mentais feitas 
involuntariamente, o estudo comparativo é a passagem do involuntário ao voluntário, ou seja, é a verificação e a comprovação daquilo que havia sido sugerido pela intuição. O deslindamento das operações textuais que tentamos aqui operar não tira o gosto da leitura, pelo contrário, ele oferece ao leitor a compreensão dos mecanismos de criação que o ajudam a incrementar as possibilidades de sentido de um texto, dando-lhe consciência da polissemia que distingue uma obra de arte verbal de uma obra meramente informativa.

A hipótese da qual partimos foi sugerida pelo próprio Murilo num poema sintomaticamente intitulado "Texto de informação": "Francispongei-me". Este primeiro hemistíquio do decassílabo que fecha o poema (o outro é "Mondrianizei-me") poderia ser apenas uma boutade, uma brincadeira, uma pista falsa. Mas tendo estudado (FIÚZA MOREIRA, 2000) a obra de Ponge, como tenho feito com a de Murilo, pude perceber que a "informação" é verdadeira, no que tange à sua poética da fase européia. $\mathrm{O}$ trabalho, portanto, seria (e o foi) de criar um repertório, além de temático, de procedimentos de linguagem, pois é no funcionamento desta que as semelhanças se
evidenciam.

É bem verdade que o repertório de procedimentos de linguagem (intertexto com o dicionário, neologismos, jogos paronomásticos, metalinguagem etc.) que foi seguido poderia ser "licado a outros poetas de outras línguas ocidentais, afinal, a "literatura ocidental é um tecido de relações" (Octávio Paz). E foram exatamente alguns dos nós que atam os fios deste tecido que tentamos
mostrar como foram atados.

A aproximação da obra de Murilo da obra de Ponge não a diminui, não o transforma num epígono tropical às margens do Tibre.
Pelo contrário. Ao ser comparada, sua obra ganha corpo, tonifica-se, "delimita e define sua identidade". Ao "francisponjar-se", ele deu frescor, alegria e requinte à poesia brasileira, aboliu os compartimentos de gênero, ganhou novos leitores - aqueles que se intimidavam com as imagens ousadas demais de seus versos à luz do Surrealismo. Seu estilo "haché" (Merquior) ganha conectores lógicos, sem abdicar, no entanto, do apuro formal ao passar para a prosa e acrescentar novos recursos numa idade em que boa parte dos poetas ou já parou de escrever ou se repete. 


\section{Referências}

AQUIEN, Michèlle. Dictionnaire de poétique. Paris: Le Livre de Poche, 1993.

ARISTÓteles, HORÁCIO, LONGINO. A poética Clássica. São Paulo: Cultrix, [197-].

BARBOSA, João Alexandre. A imitação da forma - uma leitura de João Cabral de Melo Neto. São Paulo: Duas Cidades, 1975.

BAUDELAIRE, Charles. Petis poèmes en prose (Le Spleen de Paris). Paris: Gallimard, 1973.

BAUDELAIRE, Charles. As flores do mal. Trad. Ivan Junqueira. Rio de Janeiro: Nova Fronteira, 1985.

BERGEZ, Daniel, GÉRAUD, Violaine e ROBRIEUX, Jean-Jacques. Vocabulaire de l'analyse littéraire. Paris: Natan. 1994.

BERNARD, Suzanne. Le poème em prose - de Baudelaire à nos jours. Paris: A-G. Nizet, 1959.

CAMPOS, Haroldo. Metalinguagem \& outras metas. 4. ed. São Paulo: Perspectiva, 1992.

CANDIDO, Antonio. A educação pela noite e outros ensaios. 3. ed. São Paulo: Ática, 2000.

CASTAÑON GUIMARÃES, Júlio. Territórios/conjunções - poesia e prosa críticas de Murilo Mendes. Rio de Janeiro: Imago, 1993.

CAStañon GUIMARÃES, Júlio (org.). Murilo Mendes 1901-2001. Juiz de Fora: CEMM-UFJF, 2001.

COMPAGNON, Antoine. O demônio da teoria - literatura e senso comum. Belo Horizonte: UFMG, 2001.

CORREIA DE ARAÚJO, Laís. Murilo Mendes - ensaio crítico, antologia, correspondência. São Paulo: Perspectiva, 2000.

FIÚZA MOREIRA, Fernando. L'écriture de Ponge et de Cabral. Thèse de Doctorat. Université Stendhal Grenoble-3, 2000.

FRIEDRICH, Hugo. Estrutuda da lírica moderna. 2. ed. São Paulo: Duas Cidades, 1991.

GENETTE, Gerard. Mimologiques. Paris: Seuil, 1976. 
GLEIZE, Jean-Marie. La poésie - textes critiques - XIVe-XXe Siècle. Paris: Larousse, 1995.

JAKOBSON, Roman. Lingüística e comunicação. São Paulo: Cultrix, [197-]

KOTHE, Flávio R. Fundamentos da teoria literária. Brasília: UNB, 2002.

MENDES, Murilo. Poesia completa e prosa. Rio de Janeiro: Nova Aguilar, 1995.

ORIOL-BOYER, Claudette. L'écriture du texte - téorie, pratique, didatique. Thèse de doctorat d'État, Université de Paris VIII, 1989.

PAZ, Octávio. Point de convergence - Du romantisme à l'avantgarde. Paris: Gallimard, 1976.

PONGE, Francis. Oeuvres complètes. v. 1. Paris: Gallimard (La Pléiade), 1999.

RIBEIRO, Ivan Procópio e PINHO NEVES, José Alberto (org.). Murilo Mendes - o visionário. Juiz de Fora: EDUFJ, 1997.

SOLLERS, Philippe. Francis Ponge. Paris: Seghers, 1963.

WEINTRAUB, Fábio. Murilos de vento - Cognição e vertigem em Murilo Mendes. Revista Cult, $\mathrm{n}^{\circ} 46$, maio de 2001. 